\title{
Research on Mixed Teaching of University Computer in MOOC and Rain Classroom
}

\author{
Dongmei Fan, Lu Zhang \\ Shandong Xiehe University, Jinan, Shandong, P.R. China,250109
}

\begin{abstract}
MOOC is a new teaching method that has emerged with the development of Internet information technology. It has realized the platform design with multimedia interactive network as the medium and virtual reality and hypermedia as the real technology theme. We can carry out information dissemination of remote digital satellite video IP multicast technology. This article will analyze the problems existing in the current situation of university computer teaching, and put forward the idea of adding MOOC and rain classroom to university computer basic mixed teaching. The author will put forward reasonable suggestions based on the application of MOOC and Rain Classroom.
\end{abstract}

\section{INTRODUCTION}

Compared with the traditional teacher-oriented classroom teaching mode, the teaching method combining MOOC and Rain Classroom is more suitable for college students currently receiving education. Integrating the teaching mode of MOOC and Rain Classroom into basic computer teaching research in universities can improve the quality of teaching while improving students' ability to master basic computer knowledge. In addition, this will also help improve students' practical ability and make them socially creative.

\section{MOOC AND RAIN CLASSROOM ARE INTEGRATED INTO THE BACKGROUND OF UNIVERSITY COMPUTER TEACHING}

The key task of informatization modern education reform is to complete the informatization reform of teaching mode. MOOC and Rain Classroom, as a teaching model that uses information technology under the background of the new era, are of great significance to the reform of university computer teaching models. Advanced teaching methods such as MOOC, blended teaching, and smart classroom have been developed in China for a long time, which is of great significance to the cultivation of comprehensive talents with both theory and practice in Chinese universities. Applied research people are talents with a solid theoretical foundation and strong practical ability. They can correctly understand the relationship between theoretical development and labor practice, and fully understand that theory and practice are of great significance to personal growth and even economic and social development. They have correct working attitudes, correct professional ethics and life values, and are senior talents with high overall quality and strong comprehensive abilities. Rain Classroom has added WeChat, PPT and other information-based teaching tools into classroom teaching, and has been widely recognized by all sectors of society. According to the university computer teaching tasks and reality, this article discusses the method of integrating MOOC and Rain Classroom into university computer teaching.

\section{Current Teaching Status of UNIVERSITY COMPUTER BASIC COURSES}

\subsection{The Teaching Content is Complex and Rich}

The teaching content of basic computer courses in Chinese universities has the characteristics of fast update rate and huge amount of knowledge. It specifically includes the basic knowledge of computer, the use of Office software, basic knowledge of network, operating system, etc. College computer teaching generally has fewer hours, more teaching content, and insufficient consideration of theory and practice teaching. In general, a teacher teaches more students in each class. Therefore, teachers cannot take care of each student's learning situation, and students cannot master all the content.

\subsection{Student Levels Vary Greatly in Different Regions}

University students come from different provinces and municipalities, and their respective levels of computer education in their previous educational experience are different. As a result, different students have different levels of mastery of computer technology. Computer classroom teaching under the traditional teaching mode adopts a centralized teaching management method, which 
needs to be completed at a fixed time and place. The traditional teaching model is passive, the teacher is the main body of the classroom, and the students passively participate in the teacher's teaching activities. This will result in different levels of knowledge and learning progress of each student. Moreover, because the individual basic qualities and personality differences of the student groups are not the same, it is not conducive to teaching students in accordance with their aptitude to make personalized teaching plans for students.

\subsection{Teaching Content is Out of Touch with Production Practice}

Due to the fast update rate of computer technology, the teaching content cannot be consistent with the changes in reality. Some of the teaching machines in China still use Windows XP system, while higher versions of the operating system are commonly used in the market. In this way, the theoretical knowledge of students' learning is different from the actual application, and the practical significance of learning is lacking.

\section{The Concept AND Characteristics of MOOC}

The basic definition of MOOC is that Massive Open Online Course is an online class aimed at the masses, and people can learn online courses through the Internet. Nowadays, MOOC has realized the platform design with multimedia interactive network as the medium and virtual reality and hypermedia as the real technology theme. We can carry out information dissemination of remote digital satellite video IP multicast technology.

With the development of constructivist learning theory, the research direction of educational multimedia has been extended to teaching design thinking with learning as the main. This learning refers to gradually shifting the focus of learning to independent learning by students. Constructivist theory sets the service object of the design of the learning process as students, and realizes the education of students by means of interactive penetration of multiple subject knowledge. While allowing students to develop their own creativity and imagination, use today's effective multimedia to broaden students' information sources. Constructivist learning theory enriches the practical application of educational multimedia in the process of tutoring students, and provides effective multimedia support for modern education and teaching.

This requires giving full play to the advantages of the multimedia teaching model to cultivate talents with solid theoretical foundation and strong practical ability. They can correctly understand the relationship between theoretical development and labor practice, and fully understand that theory and practice are of great significance to personal growth and even economic and social development. They have correct working attitudes, correct professional ethics and life values, and are senior talents with high overall quality and strong comprehensive abilities. During the teaching period, the emphasis is on cultivating students' practical ability. Using case teaching, teamwork, task-driven and other methods can subtly cultivate students' unity, cooperation and practical ability. Taking advantage of the wide spread of the Internet and the convenient and quick access to resources can realize the sharing of excellent teaching resources and broaden students' knowledge acquisition channels. In the process of teaching, teachers should cultivate students' radiant thinking mode, appropriately quote domestic and foreign excellent theoretical viewpoints, make up for the shortcomings in teaching technology, realize the dynamic development of the entire multimedia education system for students, and benefit students for life. Teachers also need to use the interactive features of multimedia to complete auxiliary tests on the computer to realize the organic integration of summative evaluation and formative evaluation as a whole. As the method of opening educational resources, MOOC can enrich the teaching mode and make student learning no longer restricted by space and time. Students can obtain excellent teaching resources from different time and space from all over the world, enrich their learning content, change their learning thinking, and enhance learning effects.

\section{RESEARCH ON APPLICATION OF RAIN ClASSROOM IN UNIVERSITY COMPUTER BASIC COURSE}

\subsection{Academic Analysis}

Before teaching the basic computing courses in universities, we must focus on investigating the situation of each student. We found that there are mainly two situations. The first is that the personal qualities of the students are different, and the level of learning basic computer knowledge is also different. The second is that the students' initiative in learning computer technology is weak and passive. In the stage of autonomous practice arranged by the teachers in the computer classroom, the students' autonomous learning is not well-targeted and the problem of inattention in class occurs. Otherwise, the college has limited time to practice on the computer and lack of opportunities to consult students, which will make students increasingly unable to keep up. In addition, this also makes the teaching task impossible to complete successfully, causing students to gradually lose confidence in learning computer technology, and affect the final teaching effect.

\subsection{The Specific Implementation Process of Rain Classroom}

Before giving lectures, teachers should make arrangements for instructional design, make PPT courseware for classroom use, and prepare other audio and video software that needs to be used. When introducing the multimedia teaching mode into the teaching of comparative computer, we should pay attention to highlight the key problems of classroom teaching and explain the difficult problems of teaching. This requires teachers to give full play to the advantages of the 
information technology teaching model to cultivate talents with a solid theoretical foundation and strong practical ability. Teachers need to focus on cultivating students' practical ability during the teaching period, and use case teaching, teamwork, task-driven and other methods to subtly cultivate the unity, cooperation and practical ability of the police. Use the advantages of the wide spread of the Internet and the convenient and quick access to resources to realize the sharing of excellent teaching resources and broaden students' knowledge acquisition channels. In the process of teaching, teachers should cultivate students' radiating way of thinking, appropriately quote domestic and foreign excellent theoretical viewpoints, make up for the shortcomings in teaching technology, realize the dynamic development of the entire information technology and computer education system, and benefit students for life. After the teacher has established the Rain Classroom to teach, students can sign in to enter the Rain Classroom by scanning the $\mathrm{QR}$ code or entering the password. The teacher arranges the teaching method and the order of teaching according to the actual needs of teaching. Teachers can briefly introduce the key and difficult content of this lesson. If students don't understand, they can click the "Don't understand" button to give feedback to the teacher in time. The teacher will receive feedback from the students on the client, so that it is convenient for the teacher to adjust the teaching progress according to the actual situation of the students. Students explore learning methods by themselves, and the teacher is on the sidelines to help students become the masters of the classroom, which is also a good way to improve students' learning effects. Teachers can divide several groups to let students who learn better serve as group leaders. To a large extent, students with better academic performance have their own learning methods and a certain degree of self-control, and they can be better qualified for the position of study leader. The teacher assigns the preparatory tasks first, so that they can exchange and discuss their opinions and difficult problems in class, and the group leader will summarize them. In the second half of the class, the teacher focused on answering questions summarized by the group leader. In this way, it can not only improve students' learning enthusiasm and learning confidence, but also accurately grasp the problems encountered by students and improve efficiency and teaching quality. This kind of teamwork can also cultivate students' sense of teamwork and cooperation, enhance the friendship between students, and help promote class harmony. A class with a harmonious atmosphere can provide students with a comfortable learning environment and help students calm down and learn. After completing the learning task, the students report through individual presentations or in groups. During the reporting and presentation process, a bullet screen can be opened to allow the whole class to participate in the discussion, thereby increasing the participation and enthusiasm of the students in learning. After each group report is over, let the students from other groups comment and ask questions. The instructor will make a final summary and point out the problems, and give appropriate points or deductions for the performance of each group.

\section{MOOC-BASED UNIVERSITY COMPUTER BASIC COURSES}

We need to establish a harmonious, stable and good teacher-student relationship. From the perspective of traditional education, teachers need to be dignified and teachers need to keep a certain distance from students. This is indeed conducive to classroom management, but it is not conducive to students asking questions after class. Some students with average grades or timid and introverted will resist asking teachers for questions. In consequence, teachers need to be as kind and patient as possible, respect the wishes of students, and shorten the distance between themselves and students. Teachers need to express that they welcome students to come to ask questions and consult difficult problems. Consolidation after class is a very important aspect, and the most direct thing is to give feedback in the problem. If there is a wrong question, there must be some kind of problem. Sometimes students will find that they may have made a calculation error in a certain part of their carelessness or made a mistake in reviewing the question. However, in most cases, the knowledge points are not sufficiently reliable and accurate enough to master and use. At this time, teachers need correct guidance and help on the side. Though this kind of feedback is two-way, and it mainly relies on the students to take the initiative to ask questions and feedback, so teachers need to be as kind as possible.

When assigning homework, teachers should try to avoid less meaningful homework. Teachers need to arrange more homework that is conducive to improving students' learning quality, so that students can spend more time on the consolidation and improvement of other subjects and other teaching knowledge points. Teachers need to reduce the burden on students and help students establish values that grasp the key points of the problem. Students can discuss and share classroom content on MOOC, complete assignments assigned by teachers, and comment on each other. Teachers supervise students' teaching work and assign homework to further guide students' communication work. Although MOOC has many advantages, there are still some difficult problems in comparison with traditional teaching methods. Among them, the most obvious is the lack of immersive feeling, and students cannot perceive the teacher's enthusiasm for teaching. This way of using video teaching and learning makes it impossible for teachers to supervise students' learning, which is not conducive to students' improvement of learning ability. According to the teaching tasks carried out by the MOOC method, it can also be found that the students participating in the learning will choose the learning process at will because of their personal preferences. This is not conducive to the implementation of the overall teaching plan.

Its adverse effects are mainly manifested in three aspects. First of all, the MOOC teaching mode makes most students have no patience to watch the entire teaching video completely. They often use fast forward or drag the progress bar, and they simply cannot master the entire teaching process. Secondly, students use less learning time than expected and they are not focused. Thirdly, some 
students' learning concepts have not changed from the traditional teaching methods of teachers, they are still used to traditional teaching methods.

\section{ConCLUSION}

The remote teaching method of MOOC combined with the multimedia teaching method of Rain Classroom can promote students to learn computer knowledge, and facilitate students of different levels to master the appropriate learning methods for themselves and conduct timely review. The use of Internet resource sharing and wide access channels is conducive to enriching the channels for students to improve themselves and changing the traditional single teacher work model. Utilizing the advantages of multimedia can give full play to students' learning initiative, imagination and creativity, and help students gain richer literary knowledge, expand their learning, and complete teaching tasks.

\section{ACKNOWLEDGMENT}

Project: This paper is "University Computer MOOC + SPOC Teaching Mode Reform Research and Practice", a teaching reform project of Shandong Xiehe University.

Project number:2019xh20

\section{REFERENCES}

1. Sun Yazhi. Research on MOOC's flipped classroom teaching reform in "University Computer Fundamentals"[J]. Knowledge Economy, 2020(16): $148+150$

2. Li Lijie. Research on hybrid teaching of university computer foundation based on MOOC and Rain Classroom[J]. Digital Technology and Application, 2020, 38(05): 209-210.

3. $\mathrm{Hu}$ Lingyan. Research on "flipped classroom+SPOCs+MOOC" hybrid teaching based on university computer teaching reform[J]. Contemporary Educational Practice and Teaching Research, 2020(08): 21-22.

4. Ye Zhanghao. Research on the Teaching Reform of Computer Basic Courses Based on the Hybrid Model of "MOOC + Rain Classroom"[J]. Software, 2020, 41(04): 293-296.

5. Liu Hua, Zhou Jing. The reform and practice of the flipped classroom hybrid teaching model based on improving students' application ability: Taking university computer basic courses as an example [J]. High Education Journal, 2019(23): 125-127+130 .

6. Geng Yu. The application of MOOC + SPOC mixed teaching mode in university computer basic course teaching $[\mathrm{J}]$. Journal of Xiangyang Vocational and Technical College, 2017, 16(06): 51-52+59.

7. Gou Yan, Zhao Xiwu. "University Computer Fundamental One" Flip Classroom Teaching for MOOC to Land [J]. Computer Education, 2016(04):
110-113.

8. Zhang Chunying, Liu Ying, Zhao Yanjun. Research on the "University Computer Foundation" flipped classroom teaching model based on "MOOC+SPOC" $[\mathrm{J}]$. Industry and Information Education, 2016(03): 63-69.

9. Zhan Dechen. "University Computer" "MOOC + SPOCs + Flipped Classroom" mixed teaching reform implementation plan[J]. Computer Education, 2016(01): 12-16. 